Gut, 1971, 12, 208-211

\title{
The prognosis and risk of missing malignant disease in patients with unexplained and functional diarrhoea
}

\author{
C. F. HAWKINS AND R. COCKEL \\ From the Queen Elizabeth Hospital, Birmingham
}

SUMMARY One hundred and sixty-three patients who had been diagnosed as suffering from diarrhoea without an organic cause were followed up to assess the risk of missing malignant disease. Three patients with carcinoma, two involving the stomach and one the colon had escaped diagnosis and the reasons for this are given. Prognosis in the others was usually good.

Unexplained chronic diarrhoea is a problem in every gastrointestinal clinic. Diagnoses given to such patients cover a very babel of terminology: nervous diarrhoea, irritable bowel, spastic colon, mucous colitis, dyskinesia of the colon, mucomembraneous colic, lienteric diarrhoea, non-specific diarrhoea, and even functional enterocolonopathy. However extensive the investigations, the spectre of a missed diagnosis, such as carcinoma, is present, especially in the middle-aged. The number of undiagnosed patients depends to some extent on the intensity of the investigation and upon the attitude of the physician. Some readily accept a diagnosis of nervous diarrhoea when no positive evidence of psychogenic origin can be obtained, while others are more critical and call such diarrhoea unexplained. In 1,000 general medical outpatients seen by one of us (C.H.F.) in 1955, among the patients encountered with diarrhoea there were three patients with carcinoma of rectum or colon; three with diverticular disease of colon; nine with ulcerative colitis (including proctitis); three with Crohn's disease; two with idiopathic steatorrhoea; one with amoebic dysentery; and 17 patients with unexplained diarrhoea with probable irritable colon in five of these.

The following study has been carried out to determine the outcome in patients labelled as suffering from unexplained diarrhoea and to assess the risk of missing a diagnosis such as neoplasm.

\section{Selection of Patients and Method of Enquiry}

One hundred and sixty-three patients with chronic diarrhoea of more than six weeks' duration were sent a questionnaire from two to 20 years after their Received for publication 3 November 1970. first outpatient attendance. They had been selected at the time of first attendance after investigation had failed to reveal an organic cause for the diarrhoea, so that cases where a definite diagnosis was established later were included. This selection, being prospective, avoided the bias which would occur if cases were collected retrospectively. Only patients with obvious diarrhoea who had three or more loose stools daily were included, the consistency being regarded as important as the frequency of the motions. This avoided borderline cases, for the normal range of bowel action in the healthy varies from three times daily to three times weekly (Connell, Hilton, Irving, Lennard-Jones, and Misiewicz, 1965). Cases of spurious diarrhoea were excluded by rectal examination. A detailed history, bearing in mind stigmata of malabsorption such as glossitis, loss of weight, and lassitude had been taken. Routine investigations usually included haemoglobin and ESR, examination of stools, rectal examination, sigmoidoscopy, and barium enema; barium studies of the small intestine were carried out whenever indicated-the index of clinical suspicion for malabsorption being high. The only treatment given was reassurance and antispasmodics such as propantheline. Although all cases fulfilling these criteria during the period of 20 years were not included because of inadvertent omission, no other selection occurred.

The questionnaire was short and simple, the questions asked being:

1 Do you still have diarrhoea (looseness of the bowels)?

2 If not, when did it stop and what do you think cured it?

3 Have there been any developments or has any- 
thing further come to light; or have you been to another hospital about the diarrhoea?

4 What is the condition of your general health at present?

Plenty of space was given for patients to fill in answers and the letter finished by stating 'any further comments you may wish to make may be written on the other side of the letter'. A franked envelope was enclosed for the reply. When necessary a further letter was sent requesting more details or an outpatient appointment made. When no answer was obtained from a postal questionnaire, the patients or their relatives were visited by a medical social worker or details obtained from the general practitioner or local executive council. Information about death certificates was provided by the Registrar General's Office.

From replies to the questionnaire, a patient's diarrhoea was classified as (1) continuous, (2) occasional or intermittent, and (3) cured. Subsequent relevant organic diagnoses were critically reviewed and causes of death ascertained as accurately as possible. Examination of all original case notes provided details such as the initial symptoms, age, and presence of abdominal pain.

We had hoped to review and investigate again all those who still suffered from diarrhoea. However, many whose diarrhoea had subsided or only caused inconvenience were reluctant to have such tests as sigmoidoscopy repeated, though they filled in the questionnaire conscientiously. The 30 patients selected from those 81 who still had diarrhoea who did attend were interrogated with a coded questionnaire, examined completely, and given a sigmoidoscope examination; faeces and blood were studied in the laboratory. Where appropriate, further radiographs were taken and a few were admitted to hospital for other investigations. To test for the presence of possible hypolactasia, a condition described since the original investigations were performed, a sample of 22 patients who had diarrhoea at the time of this study were sent packets of $50 \mathrm{~g}$ of glucose and $50 \mathrm{~g}$ lactose labelled ' $\mathrm{A}$ ' and ' $B$ '. They were asked to drink the sugars dissolved in water on separate occasions and to note occurrence of diarrhoea or abdominal symptoms in the following 12 hours.

\section{Results}

One hundred (61.5\%) patients were female and 63 $(38.5 \%)$ were male. Investigations had been performed as an outpatient in $131(80.5 \%)$ and in hospital in $32(19.5 \%)$. The ages of the patients when first seen ranged from 13 to 76 years (Fig. 1) with a mean of 43.8 years. Age at the onset of symp-
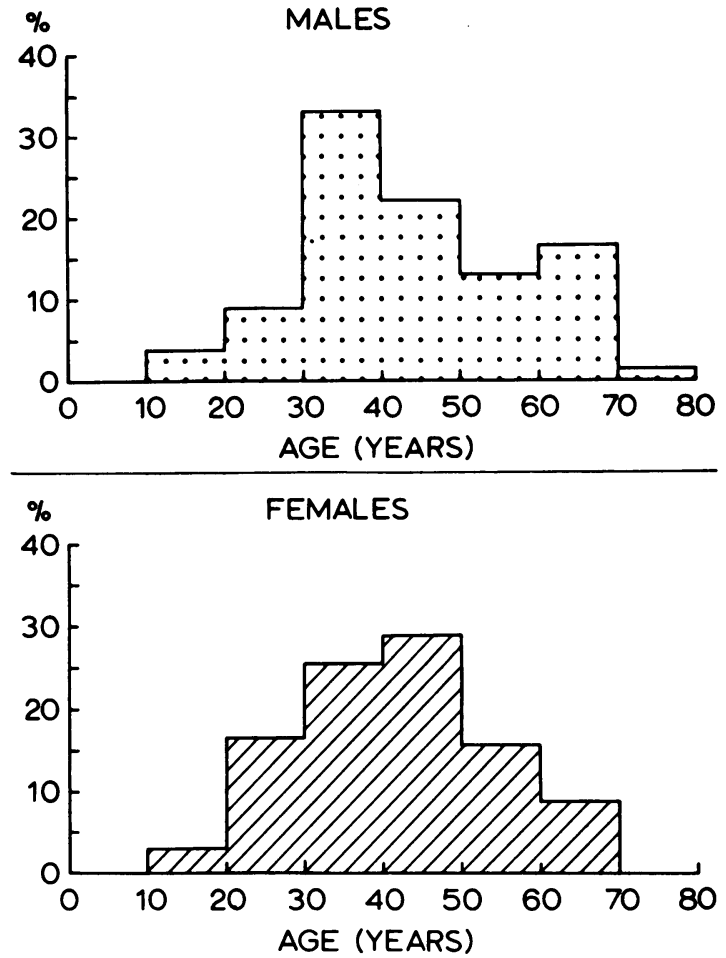

Fig. 1 Ages of patients when first seen

toms varied between 5 and 75 years, the mean being 35.2 (Fig. 2), with up to 40 years (mean 7.8 years) between the onset of symptoms and the patient's appearance at hospital.

The follow up in 163 patients revealed that diarrhoea had ceased in 63 patients $(38.5 \%)$, had become intermittent or occasional in $47(28.8 \%)$, and was persistent in $34(20.8 \%)$. There was a new gastrointestinal diagnosis in six patients $(3.7 \%)$ : seven $(4.3 \%)$ had died from an unrelated cause and six $(3.7 \%)$ could not be traced.

Diarrhoea had ceased within one year of investigation in $35 \%$ of the 163 patients, and within five years in $60 \%$. There was a remission in other patients who had suffered from diarrhoea for as long as 25 years. Two continued to have diarrhoea for 14 and 16 years, then one had a stroke and the other an attack of diverticulitis, and symptoms disappeared. The duration of symptoms before investigation bore no direct relationship to the time when diarrhoea ceased, though those with a short history tended to fare better.

Intermittent or occasional diarrhoea occurred in 47 patients $(28.8 \%)$ many of whom improved after investigation and relied upon tablets to control 

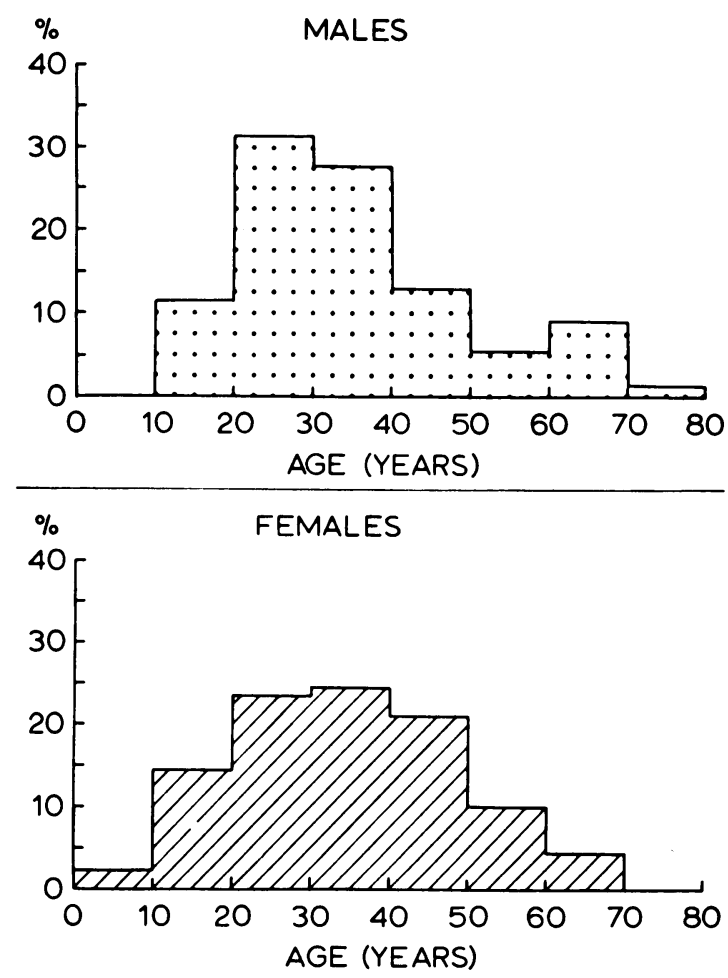

Fig. 2 Age at the onset of symptoms; $16.6 \%$ of the male patients and $14.5 \%$ of the female patients developed symptoms over the age of 50 .

symptoms. Again there was no direct relationship between duration and severity of symptoms before investigation and the course afterwards. Drugs used by patients in this group comprised propantheline, codeine, kaolin, and various proprietory drugs containing opiates, the last being particularly popular. Thirty-four patients $(20.8 \%)$ continued with persistent diarrhoea until the time of this study. Again, the duration of diarrhoea before investigation was unrelated to the likelihood of developing persistent diarrhoea. Abdominal pain was a major complaint of $84(51.5 \%)$ of the 163 patients when first seen. This was usually in the lower half of the abdomen and eased by defaecation.

A new diagnosis had been made in six patients $(3.7 \%)$. Carcinoma of the stomach was discovered in two less than one year and four years after the initial consultations. Carcinoma of the colon occurred in two others; in one it presented two years after investigation but 15 years after the onset of symptoms, and in the other it was probably incidental as it was found six years after investigation and 21 years after the onset of symptoms. The diag- nosis of ulcerative colitis and probable pancreatic steatorrhoea had arisen in two other patients. The patient with ulcerative colitis developed typical colonic changes five years after the onset of symptoms and three years after normal sigmoidoscopy. A diagnosis of pancreatic steatorrhoea was made from the macroscopic and microscopic appearance of the stool in a patient who refused further investigations. Lactase deficiency was perhaps a factor in the diarrhoea in $8 \%$ of those patients who still suffered from diarrhoea. Of the 22 patients who were tested with the trial packets of sugar, seven considered that glucose and four that lactose aggravated the diarrhoea. Lactose tolerance tests were performed on the latter but a flat curve was only found in two of the four. The adverse effects of both glucose and lactose in the others was probably due to non-specific or psychogenic factors as patients with irritable bowel commonly attribute worsening of their diarrhoea to various irrelevant factors.

Seven patients, apart from the three with carcinoma, had died but from conditions unrelated to the gastrointestinal tract such as cardiorespiratory disease.

Follow up was made difficult because of the demolition and redevelopment of Birmingham during the last 15 years. Another problem was the benign nature of the disorder; patients with serious illness can be traced more easily because of their need to attend or to be admitted to hospital where their records can be traced. In spite of these problems only six patients $(3.7 \%)$ remained untraced; two were itinerant, having previously lodged in hostels, though both were known to be alive from two to four years after examination, but the remaining four were untraceable.

The influence of whether investigations were performed inside or outside hospital is suggested by the occurrence of wrong diagnoses. There were none amongst the 32 investigated as inpatients while all six new diagnoses were made in the group of 131 who were not admitted, though the difference was not statistically significant. The outpatient group contained a higher percentage of patients whose diarrhoea eventually stopped, this almost certainly being due to selection of more severely affected patients for hospital admission.

Of the 30 patients who were critically reviewed, one new diagnosis came to light, the case of probable pancreatic steatorrhoea already mentioned. Two patients had iron-deficiency anaemia, one from haemorrhoids and the other from unexplained causes, despite full inpatient investigation. Four others were admitted for re-investigation and again no alternative explanation for diarrhoea could be found. In the remaining 23 cases interrogation, 
full examination, and a wide range of blood tests also disclosed no illnesses other than those, such as bronchitis and osteoarthritis, expected in any population. The clinical features of all these conformed to the criteria used in making the diagnosis of the irritable colon syndrome.

\section{Discussion}

Organic disease can never be completely excluded. No test is infallible and neoplasms of the alimentary tract may be missed however extensive are barium studies. Furthermore, the extent of investigation is limited, particularly in young women where radiation must be kept to a minimum. The test of time is the final court of appeal, for time always reveals the error in malignant disease. It was the fear of missing this that prompted the study.

Four carcinomas amongst 163 patients were missed, though one, a carcinoma of the colon, occurred six years after investigation and was probably incidental. Another of the four was a woman with a carcinoma of the pelvic colon which was not seen by barium enema though discovered by a further enema one year later; she had suffered from apparent nervous diarrhoea for 15 years and was sent to hospital when the diarrhoea worsened after her husband died. The two others presented with diarrhoea but the cause was an otherwise symptomless carcinoma of the stomach; one was an elderly man of 76 years and loss of weight should have prompted a barium meal as well as enema; the other was a man of 36 years. Disturbance of bowel action, either constipation or diarrhoea, was recorded in 13 of 371 patients with carcinoma of the stomach described by Swynnerton and Truelove (1952). A long history, although usually pointing against malignant disease, can be misleading and occasionally patients with carcinoma of the colon may survive longer than 10 years without treatment (Waterhouse, 1969). Age is a guide though again not infallible. Three of the four patients with carcinoma were over 50 years. It is a wise clinical axiom that middle-aged and elderly patients should not be diagnosed as suffering from nervous illness unless previous episodes have occurred.
One woman with ulcerative colitis was probably missed because sigmoidoscopy was carried out during a quiescent phase. Rectal biopsy is often the only way of detecting this (Lumb and Protheroe, 1955; Matts, 1961). The man whom we suspected of having pancreatic steatorrhoea because of the naked-eye and microscopic examination of his stool refused to undergo further tests.

The diagnosis remained unknown in at least one third of all patients. Most of the rest were considered to suffer from a motility disorder of the bowel: irritable colon when colonic pain was associated with defaecation, as in 84 , and nervous diarrhoea when other nervous symptoms were present. Irritable bowel and nervous diarrhoea may be the same condition, though Chaudhary and Truelove (1961) have shown that the motility pattern in the colon is different. Other authors have commented that the irritable bowel is one of the commonest abdominal disorders (Kalser, Zion, and Bockus, 1956; Connell, 1968). However, it is inevitable that this label will be applied to some merely until new knowledge, probably biochemical, provides the correct diagnosis.

Our gratitude is due to our secretary, Mrs Janet Stephen, for her painstaking help in organizing the study and to the medical social workers at the Queen Elizabeth Hospital for tracing some of the patients.

\section{References}

Chaudhary, N. A., and Truelove, S. C. (1961). Human colonic motility; a comparative study of normal subjects, patients with ulcerative colitis, and patients with the irritable colon syndrome. Gastroenterology, 40, 1-36.

Connell, A. M. (1968). The irritable colon syndrome. Postgrad. med. J., 44, 668-671.

Connell, A. M., Hilton, C., Irvine, G., Lennard-Jones, J. E., and Misiewicz, J. J. (1965). Variation of bowel habit in two population samples. Brit. med. J., 2, 1095-1099.

Kalser, M. H., Zion, D. E., and Bockus, H. L. (1956). Functional diarrhoea; an analysis of the clinical and roentgen manifestations. Gastroenterology, 31, 629-648.

Lumb, G., and Protheroe, R. H. B. (1955). Biopsy of the rectum in ulcerative colitis. Lancet, 2, 1208-1215.

Matts, S. G. F. (1961). The value of rectal biopsy in the diagnosis of ulcerative colitis. Quart. J. Med., 30, 393-407.

Swynnerton, B. F., and Truelove, S. C. (1952). Carcinoma of the stomach. Brit. med. J., 1, 287-292.

Waterhouse, J. A. H. (1969). Personal communication. 